\title{
Reflection of Plane Waves from a Free Surface of an Initially Stressed Transversely Isotropic Dissipative Medium
}

\author{
Baljeet Singh $^{1}$, Jyoti Arora ${ }^{2}$ \\ ${ }^{1}$ Department of Mathematics, Post Graduate Government College, Chandigarh, India \\ ${ }^{2}$ B.S.A.I.T.M, Alampur, Faridabad, India \\ E-mail: bsinghgc11@gmail.com
}

Received June 23, 2011; revised July 15, 2011; accepted July 23, 2011

\begin{abstract}
The governing equations of a transversely isotropic dissipative medium are solved analytically to obtain the speeds of plane waves. The appropriate solutions satisfy the required boundary conditions at the stress-free surface to obtain the expressions of the reflection coefficients of reflected quasi-P (qP) and quasi-SV (qSV) waves in closed form for the incidence of $\mathrm{qP}$ and $\mathrm{qSV}$ waves. A particular model is chosen for numerical computation of these reflection coefficients for a certain range of the angle of incidence. The numerical values of these reflection coefficients are shown graphically against the angle of incidence for different values of initial stress parameter. The impact of initial stress parameter on the reflection coefficients is observed significantly.
\end{abstract}

Keywords: Transversely Isotropic, Dissipative Medium, Initial Stress, Plane Waves, Reflection, Reflection Coefficients

\section{Introduction}

We can not know the Earth completely by assuming mere an elastic body. If we consider various additional parameters, e.g. porosity, initial stress, viscosity, dissipation, temperature, voids, diffusion, etc., then we can understand better the interior of the Earth. Initial stresses in a medium are caused by various reasons such as creep, gravity, external forces, difference in temperatures, etc. The reflection of plane waves at free surface, interface and layers is important in estimating the correct arrival times of plane waves from the source. Various researchers studied the reflection and transmission problems at free surface, interfaces and in layered media [1-12]. The study of reflection of plane waves in the presence of initial stresses as well as dissipation is interesting. With the help of Biot [13] theory of incremental deformation, Selim [14] studied the reflection of plane waves at a free surface of an initially stressed dissipative medium. In the present paper, we studied the problem on reflection of plane waves at a stress-free surface of an initially stressed transversely isotropic solid half-space with dissipation. The reflection coefficients of reflected waves are com- puted numerically to observe the effect of initial stress.

\section{Formulation of the Problem and Solution}

Following Biot [13], the basic dynamical equations of motion in $\mathrm{x}-\mathrm{z}$ plane for an infinite, initially stressed medium, in the absence of external body forces are,

$$
\begin{aligned}
& \frac{\partial \mathrm{s}_{11}}{\partial \mathrm{x}}+\frac{\partial \mathrm{s}_{13}}{\partial \mathrm{z}}-\mathrm{P} \frac{\partial \omega}{\partial \mathrm{z}}=\rho \frac{\partial^{2} \mathrm{u}}{\partial \mathrm{t}^{2}}, \\
& \frac{\partial \mathrm{s}_{31}}{\partial \mathrm{x}}+\frac{\partial \mathrm{s}_{33}}{\partial \mathrm{z}}-\mathrm{P} \frac{\partial \omega}{\partial \mathrm{x}}=\rho \frac{\partial^{2} \mathrm{w}}{\partial \mathrm{t}^{2}},
\end{aligned}
$$

where $\rho$ is the density, $\omega=\frac{1}{2}\left(\frac{\partial \mathrm{w}}{\partial \mathrm{x}}-\frac{\partial \mathrm{u}}{\partial \mathrm{z}}\right)$ is rotational component, $s_{i j}(i, j=1,3)$ are incremental stress components, $\mathrm{u}$ and $\mathrm{w}$ are the displacement components.

Following Biot [13], the stress-strain relations are

$$
\begin{aligned}
& \mathrm{s}_{11}=\left(\mathrm{C}_{11}+\mathrm{P}\right) \frac{\partial \mathrm{u}}{\partial \mathrm{x}}+\left(\mathrm{C}_{13}+\mathrm{P}\right) \frac{\partial \mathrm{w}}{\partial \mathrm{z}}, \\
& \mathrm{s}_{13}=\mathrm{s}_{31}=\mathrm{C}_{44}\left(\frac{\partial \mathrm{u}}{\partial \mathrm{z}}+\frac{\partial \mathrm{w}}{\partial \mathrm{x}}\right), \mathrm{s}_{33}=\mathrm{C}_{33} \frac{\partial \mathrm{w}}{\partial \mathrm{z}}+\mathrm{C}_{13} \frac{\partial \mathrm{u}}{\partial \mathrm{x}},
\end{aligned}
$$

where $\mathrm{C}_{\mathrm{ij}}$ are the incremental elastic coefficients. 
For dissipative medium, elastic coefficients are replaced by the complex constants:

$$
\begin{aligned}
& \mathrm{C}_{11} \rightarrow \mathrm{C}_{11}^{\mathrm{R}}+\mathrm{iC}_{11}^{\mathrm{I}}, \mathrm{C}_{13} \rightarrow \mathrm{C}_{13}^{\mathrm{R}}+\mathrm{iC}_{13}^{\mathrm{I}}, \\
& \mathrm{C}_{33} \rightarrow \mathrm{C}_{33}^{\mathrm{R}}+\mathrm{iC}_{33}^{\mathrm{I}}, \mathrm{C}_{44} \rightarrow \mathrm{C}_{44}^{\mathrm{R}}+\mathrm{iC}_{44}^{\mathrm{I}},
\end{aligned}
$$

where, $\mathrm{i}=\sqrt{-1}, \mathrm{C}_{11}^{\mathrm{R}}, \mathrm{C}_{11}^{\mathrm{I}}, \mathrm{C}_{13}^{\mathrm{R}}, \mathrm{C}_{13}^{\mathrm{I}}, \mathrm{C}_{33}^{\mathrm{R}}, \mathrm{C}_{33}^{\mathrm{I}}, \mathrm{C}_{44}^{\mathrm{R}}$, $\mathrm{C}_{44}^{\mathrm{I}}$ are real. Following Fung [15], the stress and strain components in dissipative medium are,

$$
\mathrm{s}_{\mathrm{ij}}=\overline{\mathrm{s}_{\mathrm{ij}}} \mathrm{e}^{\mathrm{i} \overline{\mathrm{\omega}} \mathrm{t}}, \mathrm{u}_{\mathrm{i}}=\overline{\mathrm{u}_{\mathrm{i}}} \mathrm{e}^{\mathrm{i} \overline{\mathrm{\omega}} \mathrm{t}},
$$

where $(i, j=1,3)$ and $\bar{\omega}$ being the angular frequency.

With the help of Equations (3) and (4), the Equation (2) becomes,

$$
\begin{aligned}
& \overline{\mathrm{s}}_{11}=\left(\mathrm{C}_{11}^{\mathrm{R}}+\mathrm{iC}_{11}^{\mathrm{I}}+\mathrm{P}\right) \frac{\partial \mathrm{u}}{\partial \mathrm{x}}+\left(\mathrm{C}_{13}^{\mathrm{R}}+\mathrm{iC}_{13}^{\mathrm{I}}+\mathrm{P}\right) \frac{\partial \mathrm{w}}{\partial \mathrm{z}}, \\
& \overline{\mathrm{s}}_{31}=\overline{\mathrm{s}}_{13}=\left(\mathrm{C}_{44}^{\mathrm{R}}+\mathrm{iC}_{44}^{\mathrm{I}}\right)\left(\frac{\partial \mathrm{u}}{\partial \mathrm{z}}+\frac{\partial \mathrm{w}}{\partial \mathrm{x}}\right), \\
& \overline{\mathrm{s}}_{33}=\left(\mathrm{C}_{33}^{\mathrm{R}}+\mathrm{iC}_{33}^{\mathrm{I}}\right) \frac{\partial \mathrm{w}}{\partial \mathrm{z}}+\left(\mathrm{C}_{13}^{\mathrm{R}}+\mathrm{iC}_{13}^{\mathrm{I}}\right) \frac{\partial \mathrm{u}}{\partial \mathrm{x}},
\end{aligned}
$$

With the help of Equation (5), the Equation (1) becomes,

$$
\begin{aligned}
& \left(C_{11}^{\mathrm{R}}+\mathrm{P}\right) \frac{\partial^{2} \overline{\mathrm{u}}}{\partial \mathrm{x}^{2}}+\left(\mathrm{C}_{13}^{\mathrm{R}}+\mathrm{C}_{44}^{\mathrm{R}}+\frac{\mathrm{P}}{2}\right) \frac{\partial^{2} \overline{\mathrm{w}}}{\partial \mathrm{x} \partial \mathrm{z}}+\left(\mathrm{C}_{44}^{\mathrm{R}}+\frac{\mathrm{P}}{2}\right) \frac{\partial^{2} \overline{\mathrm{u}}}{\partial \mathrm{z}^{2}} \\
& +\rho \bar{\omega}^{2} \overline{\mathrm{u}}+\mathrm{i}\left[\mathrm{C}_{11}^{\mathrm{I}} \frac{\partial^{2} \overline{\mathrm{u}}}{\partial \mathrm{x}^{2}}+\left(\mathrm{C}_{13}^{\mathrm{I}}+\mathrm{C}_{44}^{\mathrm{I}}\right) \frac{\partial^{2} \overline{\mathrm{w}}}{\partial \mathrm{x} \partial \mathrm{z}}+\mathrm{C}_{44}^{\mathrm{I}} \frac{\partial^{2} \overline{\mathrm{u}}}{\partial \mathrm{z}^{2}}\right]=0 \\
& \mathrm{C}_{33}^{\mathrm{R}} \frac{\partial^{2} \overline{\mathrm{w}}}{\partial \mathrm{z}^{2}}+\left(\mathrm{C}_{13}^{\mathrm{R}}+\mathrm{C}_{44}^{\mathrm{R}}+\frac{\mathrm{P}}{2}\right) \frac{\partial^{2} \overline{\mathrm{u}}}{\partial \mathrm{x} \partial \mathrm{z}} \\
& +\left(\mathrm{C}_{44}^{\mathrm{R}}-\frac{\mathrm{P}}{2}\right) \frac{\partial^{2} \overline{\mathrm{w}}}{\partial \mathrm{x}^{2}}+\rho \bar{\omega}-2 \overline{\mathrm{w}} \\
& +\mathrm{i}\left[\left(\mathrm{C}_{13}^{\mathrm{I}}+\mathrm{C}_{44}^{\mathrm{I}}\right) \frac{\partial^{2} \overline{\mathrm{u}}}{\partial \mathrm{x} \partial \mathrm{z}}+\mathrm{C}_{44}^{\mathrm{I}} \frac{\partial^{2} \overline{\mathrm{w}}}{\partial \mathrm{x}^{2}}+\mathrm{C}_{33}^{\mathrm{I}} \frac{\partial^{2} \overline{\mathrm{w}}}{\partial \mathrm{z}^{2}}\right]=0
\end{aligned}
$$

The displacement vector $\mathbf{U}^{(\mathrm{n})}=\left(\mathrm{u}^{\mathrm{n}}, \mathrm{O}, \mathrm{w}^{\mathrm{n}}\right)$ is given by,

$$
\mathbf{U}^{(\mathrm{n})}=\mathrm{A}_{\mathrm{n}} \mathbf{d}^{(\mathrm{n})} \mathrm{e}^{\mathrm{i} \omega_{\mathrm{n}}},
$$

where (n) assigns an arbitrary direction of propagation of waves, $\mathbf{d}^{\mathrm{n}}=\left(\mathrm{d}_{1}^{\mathrm{n}}, \mathrm{d}_{3}^{\mathrm{n}}\right)$ is the unit displacement vector and $\omega_{n}=k_{n}\left[c_{n} t-\left(\mathbf{X} . \Gamma^{(n)}\right)\right]$ is the phase factor, in which $\Gamma^{(\mathrm{n})}=\left(\Gamma_{1}^{\mathrm{n}}, \Gamma_{3}^{(\mathrm{n})}\right)$ is the unit propagation vector, $\mathrm{c}_{\mathrm{n}}$ is the velocity of propagation $\mathbf{X}=(x, z)$, and $\mathrm{k}_{\mathrm{n}}$ is corresponding wave number, which is related to the angular frequency by $\bar{\omega}=\mathrm{k}_{\mathrm{n}} \mathrm{c}_{\mathrm{n}}$.

The displacement components $u^{n}$ and $w^{n}$ are written as

$$
\left(\begin{array}{c}
u^{n} \\
w^{n}
\end{array}\right)=\left(\begin{array}{c}
A_{n} d_{1}^{n} \\
A_{n} d_{3}^{n}
\end{array}\right) e^{\left[-i k_{n}\left(x \Gamma_{1}^{n}+z \Gamma_{3}^{n}-c_{n} t\right)\right]},
$$

Making use of Equation (9) into the Equations (6) and (7), we obtain a system of two homogeneous equations, which as non-trivial solution if

$$
\left(\rho \mathrm{c}_{\mathrm{n}}^{2}\right)^{2}-\left(\rho \mathrm{c}_{\mathrm{n}}^{2}\right) \mathrm{I}+\mathrm{P}_{\mathrm{n}}=0
$$

where,

$$
\begin{gathered}
\mathrm{I}=\mathrm{D}_{1}+\mathrm{D}_{2}, \mathrm{P}_{\mathrm{n}}=\mathrm{D}_{1} \mathrm{D}_{3}-\mathrm{D}_{2}^{2}, \\
\mathrm{D}_{1}=\left\{\left(\mathrm{C}_{11}^{\mathrm{R}}+\mathrm{R}\right) \Gamma_{1}^{(\mathrm{n})^{2}}\right\}+\left(\mathrm{C}_{44}^{\mathrm{R}}+\frac{\mathrm{P}}{2}\right) \cdot \Gamma_{3}^{(\mathrm{n})^{2}} \\
+\mathrm{i}\left[\left(\mathrm{C}_{11}^{\mathrm{R}}\right) \Gamma_{1}^{(\mathrm{n})^{2}}+\left(\mathrm{C}_{44}^{\mathrm{R}}\right) \cdot \Gamma_{3}^{(\mathrm{n})^{2}}\right], \\
\mathrm{D}_{2}=\left[\left(\mathrm{C}_{13}^{\mathrm{R}}+\mathrm{C}_{44}^{\mathrm{R}}+\frac{\mathrm{P}}{2}\right) \Gamma_{1}^{\mathrm{n}} \Gamma_{3}^{\mathrm{n}}+\mathrm{i}\left(\mathrm{C}_{13}^{\mathrm{I}}+\mathrm{C}_{44}^{\mathrm{I}}\right) \Gamma_{1}^{\mathrm{n}} \Gamma_{3}^{\mathrm{n}}\right], \\
=\left\{\left[\left(\mathrm{C}_{44}^{\mathrm{R}}-\frac{\mathrm{P}}{2}\right) \Gamma_{1}^{\mathrm{n}^{2}}+\mathrm{C}_{33}^{\mathrm{R}} \Gamma_{3}^{\mathrm{n}^{2}}\right]+\mathrm{i}\left[\left(\mathrm{C}_{44}^{\mathrm{I}}\right) \Gamma_{1}^{\mathrm{n}^{2}}+\mathrm{C}_{33}^{\mathrm{I}} \Gamma_{3}^{(\mathrm{n})^{2}}\right]\right\}, \\
\text { The roots } \mathrm{C}_{\mathrm{n}}^{2}=\frac{\mathrm{I}+\sqrt{\mathrm{I}^{2}-4 \mathrm{P}_{\mathrm{n}}}}{2 \rho}, \mathrm{C}_{\mathrm{n}}^{2}=\frac{\mathrm{I}-\sqrt{\mathrm{I}^{2}-4 \mathrm{P}_{\mathrm{n}}}}{2 \rho}
\end{gathered}
$$

$\mathrm{D}_{3}$

correspond to quasi-P (qP) waves and quasi-SV (qSV) waves respectively.

The above two roots give the square of velocities of propagation as well as damping. Real parts of the right hand sides correspond to phase velocities and the respective imginary parts correspond to damping velocities of qP and qSV waves, respectively. It is observed that both $\mathrm{c}_{1}^{2}$ and $\mathrm{c}_{2}^{2}$ depend on initial stresses, damping and direction of propagation $\Gamma^{\mathrm{n}}$. In the absence of initial stresses and damping, the above analysis corresponds to the case of transversely isotropic elastic solid.

\section{Reflection of Plane Waves from Free Surface}

We consider an initially stressed dissipative half-space occupying the region $\mathrm{z} \geq 0$ (Figure 1). In this section, we shall drive the closed form expressions for the reflection coefficients for incident qP or qSV waves.

The displacement components of incident and reflected waves are as,

$$
u(x, z, t)=\sum_{j=1}^{4} A_{j} d_{1}^{(j)} e^{i \omega_{j}}, w(x, z, t)=\sum_{j=1}^{4} A_{j} d_{3}^{(j)} e^{i \omega_{j}},
$$

where, 


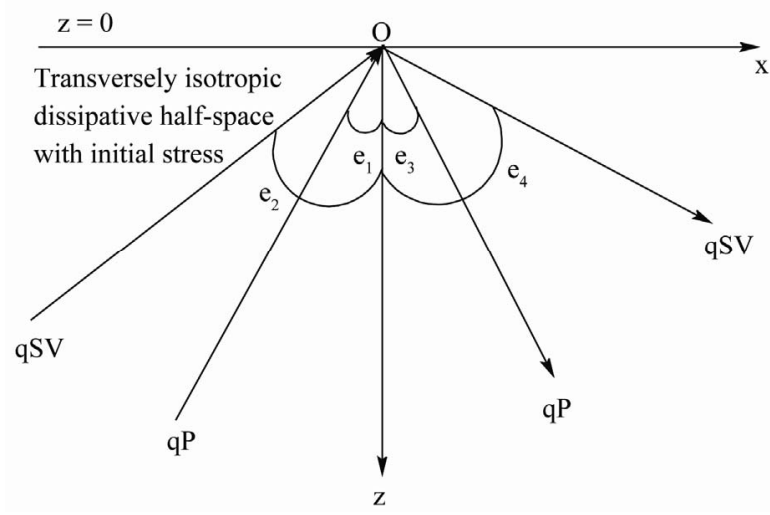

Figure 1. Geometry of the problem.

$$
\begin{aligned}
& \omega_{1}=k_{1}\left[c_{1} t-\left(\sin e_{1} x-\cos e_{1} z\right)\right], \\
& \omega_{2}=k_{2}\left[c_{2} t-\left(\sin e_{2} x-\cos e_{2} z\right)\right], \\
& \omega_{3}=k_{3}\left[c_{3} t-\left(\sin e_{3} x+\cos e_{3} z\right)\right], \\
& \omega_{4}=k_{4}\left[c_{4} t-\left(\sin e_{4} x+\cos e_{4} z\right)\right],
\end{aligned}
$$

Here, subscripts $1,2,3$ and 4 correspond to incident $\mathrm{qP}$ wave, incident $\mathrm{qSV}$ wave, reflected $\mathrm{qP}$ wave and reflected qSV wave, respectively.

In the $\mathrm{x}-\mathrm{z}$ plane, the displacement and stress components due to the incident $\mathrm{qP}$ wave

$\left(\Gamma_{1}^{(1)}=\sin \mathrm{e}_{1}, \Gamma_{3}^{(1)}=-\cos \mathrm{e}_{1}\right)$ are written as

$$
\begin{gathered}
u^{(1)}=A_{1} d_{1}^{(1)} e^{i \omega_{1}}, \\
w^{(1)}=A_{1} d_{3}^{(1)} e^{i \omega_{1}}, \\
s_{13}^{(1)}=i A_{1} Q_{4} k_{1}\left[d_{1}^{(1)} \cos e_{1}-d_{3}^{(1)} \sin e_{1}\right] e^{i \omega_{1}} \\
s_{33}^{(1)}=i_{1} k_{1}\left(Q_{3} d_{3}^{(1)} \cos e_{1}-Q_{2} d_{1}^{(1)} \sin e_{1}\right) e^{i \omega_{1}}
\end{gathered}
$$

where,

$$
\begin{aligned}
& \mathrm{Q}_{1}=\mathrm{C}_{11}^{\mathrm{R}}+\mathrm{iC}_{11}^{\mathrm{I}}, \mathrm{Q}_{2}=\mathrm{C}_{13}^{\mathrm{R}}+\mathrm{iC}_{13}^{\mathrm{R}}, \\
& \mathrm{Q}_{3}=\mathrm{C}_{33}^{\mathrm{R}}+\mathrm{iC}_{33}^{\mathrm{I}}, \mathrm{Q}_{4}=\mathrm{C}_{44}^{\mathrm{R}}+\mathrm{iC}_{44}^{\mathrm{I}} .
\end{aligned}
$$

In the $\mathrm{x}-\mathrm{z}$ plane, the displacement and stress components due to the incident qSV wave $\left(\Gamma_{1}^{(2)}=\sin \mathrm{e}_{2}, \Gamma_{3}^{(2)}=-\cos \mathrm{e}_{2}\right)$ are written as

$$
\begin{gathered}
u^{(2)}=A_{2} d_{1}^{(2)} e^{i \omega_{2}}, \\
w^{(2)}=A_{2} d_{3}^{(2)} e^{i \omega_{2}}, \\
s_{13}^{(2)}=i A_{2} Q_{4} k_{2}\left[d_{1}^{(2)} \cos e_{2}-d_{3}^{(2)} \sin e_{2}\right] e^{i \omega_{2}} \\
s_{33}^{(2)}=i A_{2} k_{2}\left(Q_{3} d_{3}^{(2)} \cos e_{2}-Q_{2} d_{1}^{(2)} \sin e_{2}\right) e^{i \omega_{2}}
\end{gathered}
$$

In the $\mathrm{x}-\mathrm{z}$ plane, the displacement and stress components due to the reflected $\mathrm{qP}$ wave $\left(\Gamma_{1}^{(3)}=\sin \mathrm{e}_{3}, \Gamma_{3}^{(3)}=-\cos \mathrm{e}_{3}\right)$ are written as

$$
\begin{aligned}
& u^{(3)}=A_{3} d_{1}^{(3)} e^{i \omega_{3}}, \\
& w^{(3)}=A_{3} d_{3}^{(3)} e^{i \omega_{3}},
\end{aligned}
$$

$$
\begin{array}{r}
\mathrm{s}_{13}^{(3)}=-\mathrm{iA}_{3} \mathrm{Q}_{4} \mathrm{k}_{3}\left[\mathrm{~d}_{1}^{(3)} \cos \mathrm{e}_{3}+\mathrm{d}_{3}^{(3)} \sin \mathrm{e}_{3}\right] \mathrm{e}^{\mathrm{i} \omega_{3},} \\
\mathrm{~s}_{33}^{(3)}=-\mathrm{iA}_{3} \mathrm{k}_{3}\left[\mathrm{Q}_{3} \mathrm{~d}_{3}^{(3)} \cos \mathrm{e}_{3}+\mathrm{Q}_{2} \mathrm{~d}_{1}^{(3)} \sin \mathrm{e}_{3}\right] \mathrm{e}^{\mathrm{i} \omega_{3},}
\end{array}
$$

In the $\mathrm{x}-\mathrm{z}$ plane, the displacement and stress components due to the reflected qSV wave $\left(\Gamma_{1}^{(4)}=\sin \mathrm{e}_{4}, \Gamma_{3}^{(4)}=\cos \mathrm{e}_{4}\right)$ are written as

$$
\begin{gathered}
u^{(4)}=A_{4} d_{1}^{(4)} e^{i \omega_{4}}, \\
w^{(4)}=A_{4} d_{3}^{(4)} e^{i \omega_{4}} \\
s_{13}^{(4)}=-i A_{4} Q_{4} k_{4}\left[d_{1}^{(4)} \cos e_{4}+d_{3}^{(4)} \sin e_{4}\right] e^{i \omega_{4}}, \\
s_{33}^{(4)}=-i A_{4} k_{4}\left(Q_{3} d_{3}^{(4)} \cos e_{4}+Q_{2} d_{1}^{(4)} \sin e_{4}\right) e^{i \omega_{4}},
\end{gathered}
$$

The boundary conditions required to be satisfied at the free surface $\mathrm{z}=0$,

$$
\begin{aligned}
& \Delta \mathrm{f}_{\mathrm{x}}=\mathrm{s}_{13}^{(\mathrm{n})}+\mathrm{e}_{13}^{(\mathrm{n})} \mathrm{P}=0, \\
& \Delta \mathrm{f}_{\mathrm{z}}=\mathrm{s}_{33}^{(\mathrm{n})}=0,
\end{aligned}
$$

The above boundary conditions are written as

$$
\begin{aligned}
& \mathrm{s}_{13}^{(1)}+\mathrm{s}_{13}^{(2)}+\mathrm{s}_{13}^{(3)}+\mathrm{s}_{13}^{(4)}+\mathrm{P}\left(\mathrm{e}_{13}^{(1)}+\mathrm{e}_{13}^{(2)}+\mathrm{e}_{13}^{(3)}+\mathrm{e}_{13}^{(4)}\right)=0, \\
& \mathrm{~s}_{33}^{(1)}+\mathrm{s}_{33}^{(2)}+\mathrm{s}_{33}^{(3)}+\mathrm{s}_{33}^{(4)}=0,
\end{aligned}
$$

The Equations (11) to (16) will satisfy the boundary conditions (18), if the following Snell, s law holds

$$
\frac{\sin \mathrm{e}_{1}}{\mathrm{c}_{1}}=\frac{\sin \mathrm{e}_{2}}{\mathrm{c}_{2}}=\frac{\sin \mathrm{e}_{3}}{\mathrm{C}_{3}}=\frac{\sin \mathrm{e}_{4}}{\mathrm{c}_{4}},
$$

and the following relations hold

$$
\begin{aligned}
& A_{1} \delta_{1}+A_{2} \delta_{2}+A_{3} \delta_{3}+A_{4} \delta_{4}=0, \\
& A_{1} \delta_{5}+A_{2} \delta_{6}+A_{3} \delta_{7}+A_{4} \delta_{8}=0,
\end{aligned}
$$

where

$$
\begin{aligned}
& \delta_{1}=\mathrm{k}_{1} \mathrm{~L}\left(\mathrm{~d}_{1}^{(1)} \cos \mathrm{e}_{1}-\mathrm{d}_{3}^{(1)} \sin \mathrm{e}_{1}\right), \\
& \delta_{2}=\mathrm{k}_{2} \mathrm{~L}\left(\mathrm{~d}_{1}^{(2)} \cos \mathrm{e}_{2}-\mathrm{d}_{3}^{(2)} \sin \mathrm{e}_{2}\right), \\
& \delta_{3}=-\mathrm{k}_{3} \mathrm{~L}\left(\mathrm{~d}_{1}^{(3)} \cos \mathrm{e}_{3}+\mathrm{d}_{3}^{(3)} \sin \mathrm{e}_{3}\right), \\
& \delta_{4}=-\mathrm{k}_{4} \mathrm{~L}\left(\mathrm{~d}_{3}^{(4)} \sin \mathrm{e}_{4}+\mathrm{d}_{1}^{(4)} \cos \mathrm{e}_{4}\right), \\
& \delta_{5}=\mathrm{k}_{1}\left(\mathrm{Q}_{3} \mathrm{~d}_{3}^{(1)} \cos \mathrm{e}_{1}-\mathrm{Q}_{2} \mathrm{~d}_{1}^{(1)} \sin \mathrm{e}_{1}\right), \\
& \delta_{6}=\mathrm{k}_{2}\left(\mathrm{Q}_{3} \mathrm{~d}_{3}^{(2)} \cos \mathrm{e}_{2}-\mathrm{Q}_{2} \mathrm{~d}_{1}^{(2)} \sin \mathrm{e}_{2}\right), \\
& \delta_{7}=-\mathrm{k}_{3}\left(\mathrm{Q}_{3} \mathrm{~d}_{3}^{(3)} \cos \mathrm{e}_{3}+\mathrm{Q}_{2} \mathrm{~d}_{1}^{(3)} \sin \mathrm{e}_{3}\right), \\
& \delta_{8}=-\mathrm{k}_{4}\left(\mathrm{Q}_{2} \mathrm{~d}_{1}^{(4)} \sin \mathrm{e}_{4}+\mathrm{Q}_{3} \mathrm{~d}_{3}^{(4)} \cos \mathrm{e}_{4}\right),
\end{aligned}
$$

and $\mathrm{L}=\mathrm{Q}_{4}+\frac{\mathrm{P}}{2}$ 
1) For incident $q P$ wave $\left(A_{2}=0\right)$,

$$
\frac{A_{3}}{A_{1}}=\frac{\delta_{4} \delta_{5}-\delta_{1} \delta_{8}}{\delta_{3} \delta_{8}-\delta_{4} \delta_{7}}, \frac{A_{4}}{A_{1}}=-\frac{\delta_{3} \delta_{5}-\delta_{1} \delta_{7}}{\delta_{3} \delta_{8}-\delta_{4} \delta_{7}},
$$

2) For incident $q S V$ waves $\left(A_{1}=0\right)$,

$$
\frac{A_{3}}{A_{2}}=\frac{\delta_{4} \delta_{6}-\delta_{2} \delta_{8}}{\delta_{3} \delta_{8}-\delta_{4} \delta_{7}}, \quad \frac{A_{4}}{A_{2}}=-\frac{\delta_{3} \delta_{6}-\delta_{2} \delta_{7}}{\delta_{3} \delta_{8}-\delta_{4} \delta_{7}} .
$$

For isotropic case, $\mathrm{C}_{11}=\lambda+2 \mu+\mathrm{P}, \mathrm{C}_{13}=\lambda, \mathrm{P}=-\mathrm{S}_{11}$, then, the above theoretical derivations reduce to Selim [14].

\section{Numerical Example}

For numerical purpose, a particular example of the material is chosen with the following physical constants,

$$
\begin{array}{ll}
\mathrm{C}_{11}^{\mathrm{R}}=2.628 \times 10^{10} \mathrm{~N} \cdot \mathrm{m}^{-2}, & \mathrm{C}_{33}^{\mathrm{R}}=1.562 \times 10^{10} \mathrm{~N} \cdot \mathrm{m}^{-2}, \\
\mathrm{C}_{13}^{\mathrm{R}}=0.508 \times 10^{10} \mathrm{~N} \cdot \mathrm{m}^{-2}, & \mathrm{C}_{44}^{\mathrm{R}}=0.385 \times 10^{10} \mathrm{~N} \cdot \mathrm{m}^{-2}, \\
\mathrm{C}_{11}^{\mathrm{I}}=1.025 \times 10^{10} \mathrm{~N} \cdot \mathrm{m}^{-2}, & \mathrm{C}_{33}^{\mathrm{I}}=0.950 \times 10^{10} \mathrm{~N} \cdot \mathrm{m}^{-2}, \\
\mathrm{C}_{13}^{\mathrm{I}}=0.425 \times 10^{10} \mathrm{~N} \cdot \mathrm{m}^{-2}, & \mathrm{C}_{44}^{\mathrm{I}}=0.325 \times 10^{10} \mathrm{~N} \cdot \mathrm{m}^{-2}, \\
\rho=7.14 \times 10^{3} \mathrm{~kg} \cdot \mathrm{m}^{-3} . &
\end{array}
$$

From Equations (23) and (24), the reflection coefficients of reflected $\mathrm{qP}$ and qSV waves are computed for the incident $\mathrm{qP}$ and $\mathrm{qSV}$ waves. The numerical values of the reflection coefficients of reflected $\mathrm{qP}$ and $\mathrm{qSV}$ waves are shown graphically in Figure 2 for incident qP wave and in Figure 3 for incident qSV wave.

For $\mathrm{P}=0$, the reflection coefficient of reflected $\mathrm{qP}$ wave oscillates for the whole range of the angle of incidence of $\mathrm{qP}$ wave as shown by solid line in Figure 2. The variations of reflection coefficients of $q \mathrm{P}$ wave for $\mathrm{P}$ $=1$ and $\mathrm{P}=2$ also change at each angle of incidence as shown by solid line with asters and solid lines with triangles, respectively. The comparison of the variations of reflection coefficients for $\mathrm{P}=0, \mathrm{P}=1$ and $\mathrm{P}=2$, shows the significant effect of initial stress on reflected $\mathrm{qP}$ wave for incident qP wave. Similarly, reflected qSV is also affected significantly due to the presence of initial stress as shown in Figure 2.

For incident qSV wave, the reflection coefficient of reflected $\mathrm{qP}$ wave first increases to its maximum value and then decreases to its minimum value at angle $\mathrm{e}_{2}=$ $45^{\circ}$ when $\mathrm{P}=0$. Thereafter, it oscillates as shown by solid line in Figure 3. The variations of reflection coefficients of $\mathrm{qP}$ wave for $\mathrm{P}=1$ and $\mathrm{P}=2$ are similar to that for $\mathrm{P}=0$. The comparison of solid line, solid line with asters and solid line with triangles shows the significant effect of initial stress on reflected $\mathrm{qP}$ wave for incident qSV wave. Similarly, reflected qSV is also affected significantly due to the presence of initial stress as shown in Figure 3.
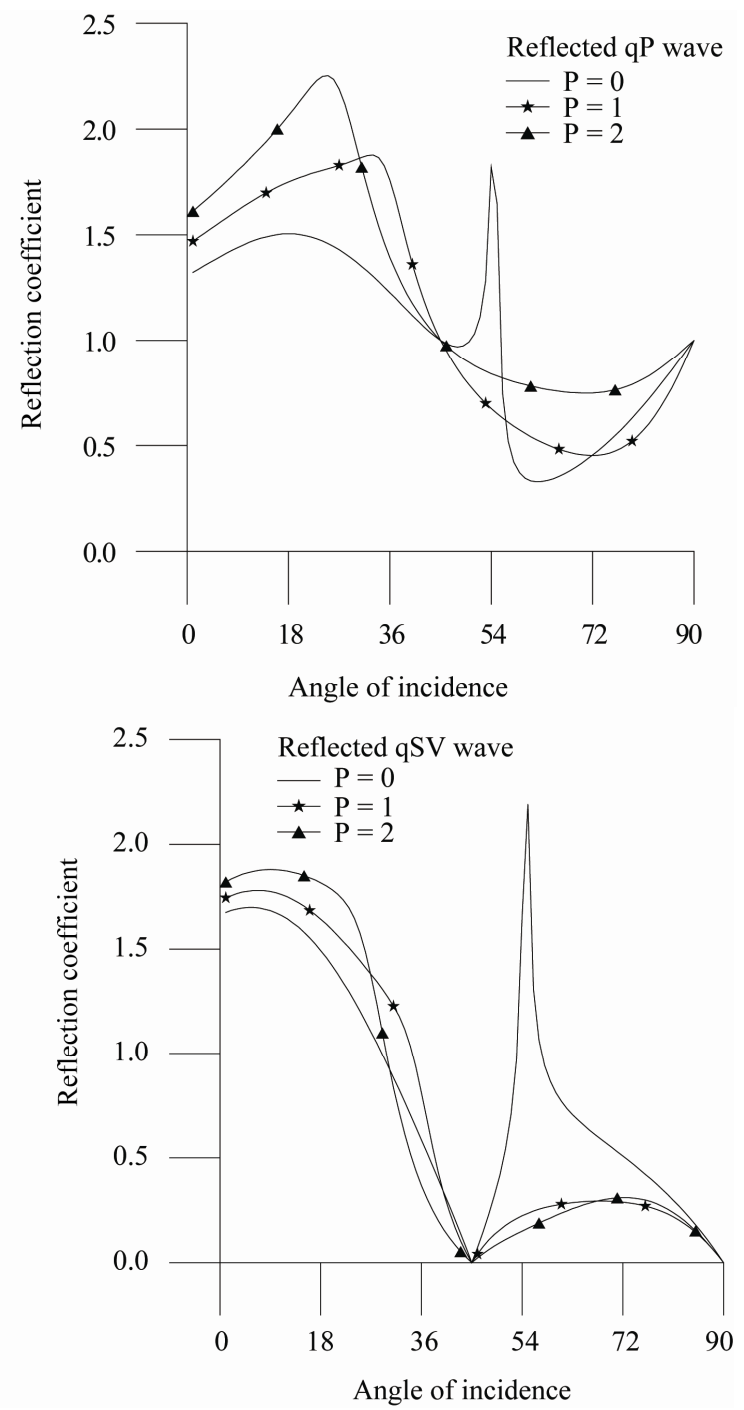

Figure 2. Variation of the reflection coefficients of $\mathrm{qP}$ and qSV waves against the angle of incidence for incidence of qP wave.

\section{Conclusions}

The reflection from the stress-free surface of a transversely isotropic dissipative medium is considered. The expressions for the reflection coefficients of reflected $\mathrm{qP}$ and qSV waves are obtained in closed form for the incidence of $\mathrm{qP}$ and $\mathrm{qSV}$ waves. For a particular material, these coefficients are computed and depicted graphically against the angle of incidence for different values of initial stress parameter. From the figures, it observed that 1) the initial stresses affect significantly the reflection coefficients of all reflected waves. 2) For incident qP wave, the critical angle for reflected qSV wave is observed at $\mathrm{e}_{1}$ $=45^{\circ}$ and for incident qSV wave, the critical angle for reflected $q P$ wave is observed also at $e_{2}=45^{\circ}$. 3) The effect of initial stresses on the reflection coefficients is 


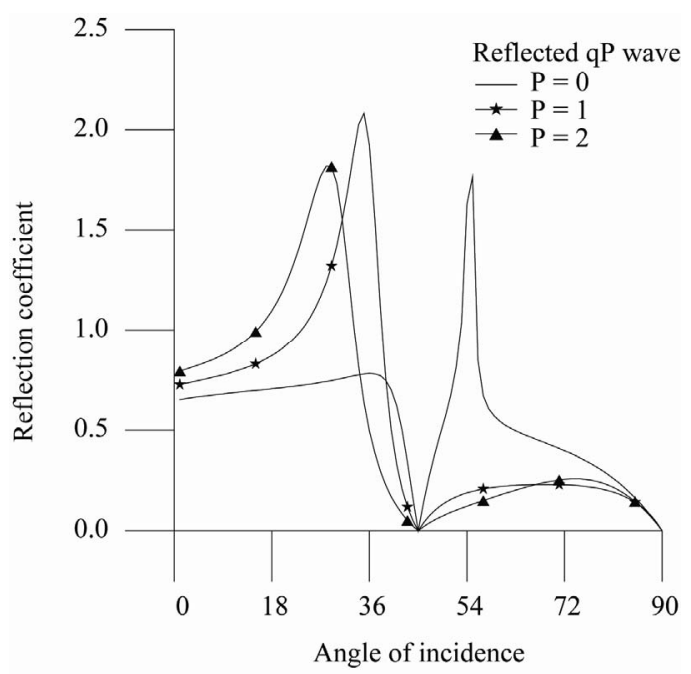

No. 1, 1965, pp. 122-131. doi:10.1190/1.1439528

[3] R. D. Tooly, T. W. Spencer and H. F. Sagoci, "Reflection and Transmission of Plane Compressional Waves," Geophysics, Vol. 30, No. 4, 1965, pp. 552-570.

[4] R. N. Gupta, "Reflection of Elastic Waves from a Linear Transition Layer," Bulletin of the Seismological Society of America, Vol. 56, 1966, No. 2, pp. 511-526. doi:10.1190/1.1439622

[5] R. N. Gupta, "Propagation of SH-Waves in Inhomogeneous Media," Journal of the Acoustical Society of America, Vol. 41, No. 5, 1967, pp. 1328-1329. doi:10.1121/1.1910477

[6] H. K. Acharya, "Reflection from the Free Surface of Inhomogeneous Media," Bulletin of the Seismological Society of America, Vol. 60, No. 4, 1970, pp. 1101-1104.

[7] V. Cerveny, "Reflection and Transmission Coefficients for Transition Layers," Studia Geophysica et Geodaetica, Vol. 18, No. 1, 1974, pp. 59-68.

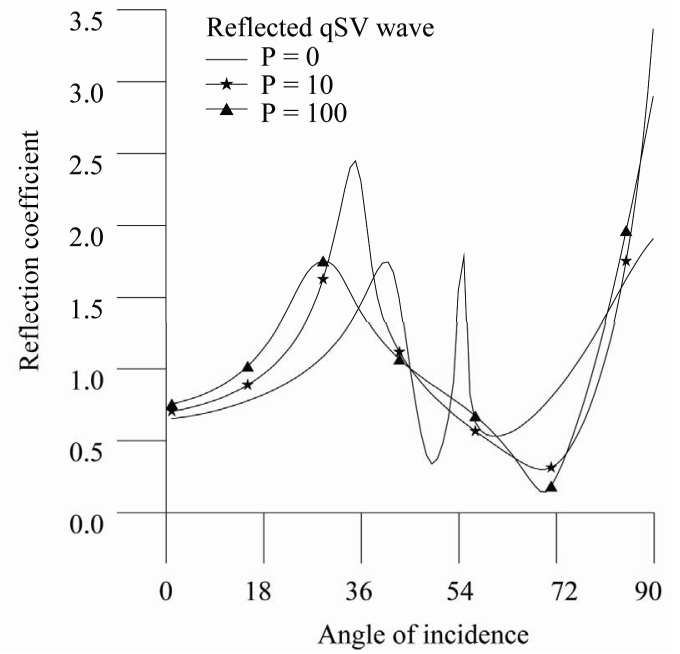
doi:10.1007/BF01613709

[8] B. M. Singh, S. J. Singh and S. D. Chopra, "Reflection and Refraction of SH-Waves and the Plane Boundary between Two Laterally and Vertically Heterogeneous Solids,” Acta Geophysica, Vol. 26, 1978, pp. 209-216.

[9] B. Singh, "Effect of Hydrostatic Initial Stresses on Waves in a Thermoelastic Solid Half-Space," Applied Mathematics and Computation, Vol. 198, No. 2, 2008, pp. 498505.

[10] M. D. Sharma, "Effect of Initial Stress on Reflection at the Free Surfaces of Anisotropic Elastic Medium," Journal of Earth System Science, Vol. 116, No. 6, 2007, pp. 537-551. doi:10.1007/s12040-007-0049-8

[11] S. Dey and D. Dutta, "Propagation and Attenuation of Seismic Body Waves in Initially Stressed Dissipative Medium,” Acta Geophysica, Vol. XLV1, 1998, pp. 351365.

Figure 3. Variation of the reflection coefficients of $q P$ and qSV waves against the angle of incidence for incidence of qSV wave.

minimum at $\mathrm{e}_{1}=45^{\circ}$ for incidence $\mathrm{qP}$ wave and at $\mathrm{e}_{2}=$ $45^{\circ}$ for incidence qSV wave.

\section{References}

[1] S. B. Sinha, "Transmission of Elastic Waves through a Homogenous Layer Sandwiched in Homogenous Media,” Journal of Physics of the Earth, Vol. 12, No. 1, 1999, pp. 1-4. doi:10.4294/jpe1952.12.1

[2] R. N. Gupta, "Reflection of Plane Waves from a Linear Transition Layer in Liquid Media,” Geophysics, Vol. 30,

[12] M. M. Selim and M. K. Ahmed, "Propagation and AtteNuation of Seismic Body Waves in Dissipative Medium under Initial and Couple Stresses," Applied Mathematics and Computation, Vol. 182, No. 2, 2006, pp. 1064-1074.

[13] M. A. Biot, "Mechanics of Incremental Deformation," John Wiley and Sons Inc., New York, 1965.

[14] M. M. Selim, "Reflection of Plane Waves at Free Surface of an Initially Stressed Dissipative Medium,” Recent Advances in Technologies, Vol. 30, 2008, pp. 36-43.

[15] Y. C. Fung, "Foundation of Solid Mechanics," Prentice Hall of India, New Delhi, 1965. 